\title{
Sırt Çantalı Gezginlerin Demografik Özellikleri ile Kişisel Gelişimleri Arasındaki Farklılığın İncelenmesi
}

\author{
Gülizar AKKUŞ \\ Kastamonu Üniversitesi, Turizm Fakültesi, Turizm Rehberliği Bölümü, Kastamonu \\ gakkus@kastamonu.edu.tr \\ ORCID ID: https://orcid.org/0000-0001-9262-2680 \\ Çetin AKKUŞ \\ Kastamonu Üniversitesi, Turizm Fakültesi, Gastronomi ve Mutfak Sanatları Bölümü, \\ cakkus@kastamonu.edu.tr \\ ORCID ID: https://orcid.org/0000-0002-6539-726X
}

Araştırma Makalesi

Geliş Tarihi: 22.07.2019

DOI: $10.31592 /$ aeusbed.595180

Revize Tarihi: 21.02 .2020

Kabul Tarihi: 24.02.2020

\section{Atıf Bilgisi}

Akkuş, G. ve Akkuş, Ç. (2020). Sırt çantalı gezginlerin demografik özellikleri ile kişisel gelişimleri arasındaki farklılığın incelenmesi. Ahi Evran Üniversitesi Sosyal Bilimler Enstitüsü Dergisi, 6(1), 173-186.

\section{ÖZ}

Turizm tüketimi, özünde kendilik hissini keşfetmeye çalışan bireyle ilgilidir. Bu keşif ise çoğu zaman olumlu bir değişim yani kişisel gelişim ile sonuçlanmaktadır. Sırt çantalı gezginlerin de seyahat şekli ve süresi göz önüne alındığında, diğer turist tiplerine nazaran seyahatleri sonrasında kendilerinde algıladıkları ya da hissettikleri değişikliklerin daha fazla olduğu söylenebilir. Bu araştırmada Türk sırt çantalı gezginlerin seyahatleri sonrasında hissettikleri kişisel gelişimi tespit edebilmek ve gezginlerin demografik özelliklerine göre kişisel gelişimlerinin farklılaşıp farklılaşmadığını belirlemek amaçlanmıştır. Evrenin belirsizliği sebebiyle kartopu örneklemesine başvurulmuştur. Veri toplama aracı olarak anket tekniği kullanılmıştır. Sirt çantalı gezginlerin kişisel gelişimlerini ölçebilmek amacıyla Chen, Bao ve Huang (2014) tarafından tasarlanan "sırt çantalı gezgin kişisel gelişim ölçeği”"nden faydalanılmıştır. Veriler 2018 yılı Eylül-Ekim aylarında yüz yüze ve çevrimiçi olarak toplanmıştır. Elde edilen verilere farklılık analizleri uygulanmıştır. Araştırma sonucunda gezginlerin cinsiyet dışında diğer tüm değişkenler açısından kişisel gelişimlerinin anlamlı farklılıklar gösterdiği tespit edilmiştir. Ayrıca yurt dışına seyahat etmiş olan sırt çantalı gezginlerin farkındalık düzeylerinin daha yüksek olduğu tespit edilmiştir.

Anahtar Kelimeler: Kişisel gelişim, demografik özellikler, sırt çantalı gezginler, Türkiye.

\section{Investigation of Difference between Demographic Characteristics and Personal Developments of Backpackers}

\begin{abstract}
Tourism consumption, in essence, is about the individual who is trying to discover the sense of self. This discovery often results in a positive change, ie personal development. Considering the type and duration of travel of the backpackers, it can be said that the changes they perceive or feel after their travels more than the other types of tourists. In this study, it is aimed to determine the personal development of the Turkish backpackers after their travels and to determine whether their personal development differs according to the demographic characteristics of the travelers. Snowball sampling was applied due to the uncertainty of the universe. Survey technique was used as data collection tool. In order to measure the personal development of backpackers, "backpacker personal development scale" designed by Chen, Bao and Huang (2014) was utilized. Data were collected face to face and online in September-October 2018. Difference analysis were applied to the data. As a result of the study, it was determined that the personal development of the travelers in terms of all variables other than gender showed significant differences. It was also found that the awareness level of backpackers who traveled abroad was higher.
\end{abstract}

Keywords: Personal development, demographic characteristics, backpackers, Turkey.

\section{Giriş}

Bağımsız seyahat eden gezginler, ilk defa akademik anlamda Cohen (1973, s.89) tarafindan "drifter (başıboş, avare, serseri)" olarak tanımlanmıştır. Riley (1988, s.313) ise bu bireylerin "uluslararası uzun süreli düşük bütçe yolcuları" olduğunu ifade etmiştir. Ancak 1990'lı yılların sonlarından itibaren "backpacker (sırt çantalı gezgin)" (Loker-Murphy ve Pearce, 1995, s.819; Wilson, 1997, s.57) ifadesi kullanılmaya başlanmıştır. Bu tabir, Riley’in yaptığı uzun tanımlamayı kısaltması ve akılda kalıcı olması sebebiyle genel bir kabul görmüştür (O'Reilly, 2006). 
Sırt çantalı gezginleri tanımlayan üç belirgin özellik bulunmaktadır. En belirgin iki özellik, yolda geçirilen zamanın uzunluğu ve seyahat şeklidir. Gezginler, daha çok aylar boyu, bazen yıl boyu seyahat etmektedir. Bu seyahatleri ise daha çok düşük bir bütçe ile geçinerek gerçekleştirmektedir. Bununla birlikte üçüncü belirgin özellikleri seyahat görevine yönelme durumlarıdır (Uriely, Yonay ve Simchai, 2002). Bu durum serendiplik (şansa bırakma) ile açıklanmaktadır. Serendiplikten kasıt, gezginlerin düşük seviyede planlama yapması, sabit olmayan bir zaman çizelgesini benimsemesi ve plan ya da güzergâhı değiştirmede esnek davranması durumudur (O'Reilly, 2006). Pearce (1990) ise sırt çantalı gezginleri "çok kısa tatillerden ziyade uzun seyahatlere çıkan, düşük bütçeli konaklamayı ve bağımsız olarak organize edilmiş esnek seyahat programlarını tercih eden, diğer gezginlerle tanışmaya önem veren, resmi olmayan ve katılımcı tatil faaliyetlerine ilgi duyan gezginler" olarak tanımlamıştır (Akt. Paris 2010, s.239). Paris de bu tanımlamaya ek olarak yerel halkla iletişim kurma isteği ve seyahat programlarında zaman, para ve destinasyon açısından esnek davranmadan bahsetmiştir (Paris, 2010).

1970'li yıllarda ortaya çıkan sırt çantalı gezginlerin hayatı yaşayışları ya da felsefeleri ve onları gezgin olma yönünde güdüleyen motivasyonları daha çok düzene karşı bir eylemi simgelemiştir. Gezginler, düzenin dayattığı çalışma hayatını benimsemeyen, özgür yaşayıp, seyahat ederek sadece temel ihtiyaçlarını karşılamaya odaklanan sosyal bir oluşum olarak değerlendirilmiştir. 21. yüzyıl ile daha çok insana yayılan bu felsefenin önüne zaman kaygısı geçmeye başlamıştır. Eski yapısına göre daha kısa zaman diliminde aynı deneyimi yaşamaya çalışan gezginlerin yerini ise artık günümüz bilgi ve iletişim teknolojileri çağının sırt çantalı gezginleri almaya başlamıştır. Öncesinde "backpacker" olarak tanımlanan sirt çantalı gezginlerin, şimdilerde "flashpacker" (Paris, 2012, s.1095) olarak nitelendiği gözlenmektedir. Flashpacker kelimesindeki packer, sırt çantalı gezgini ifade ederken, flash ön eki taşınabilir belleği simgelemektedir. Flashpacker'lar Türkçe yazında ise "dijital göçebe" (Yılmaz, 2018, s.1522) olarak tanımlanmakta olup, yanında yüksek teknolojili elektronik cihazlar taşıyan, sosyal medyayı aktif kullanıp paylaşımlar yapan ve gelir düzeyi daha yüksek bir kitleyi belirtmek amaçlı kullanılmaktadır.

1970'ler ile 2000'li yılların sırt çantalılarını ayıran en önemli farklılıklar, zaman ve teknoloji iken, 2000'li yılların başlangıcı ile 2012 yılı ile başlayan yeni dönem dijital göçebeleri arasındaki en belirgin fark ise bütçe ve teknoloji (Paris, 2012) açısından olmuştur. Teknoloji 2000'li yıllar ile sırt çantalıların hayatına girmiş ve yeni sınıflandırmalar yapılmasına sebebiyet vermiştir. Sırt çantalı gezginlerin 2000'li yılların başında kullandıkları çevrimiçi topluluklar ile haberleşme teknolojisi, 2012 y1lından itibaren yerini yeni nesil teknolojik ürünlere ve özellikle mobil internet teknolojisine bırakmıştır. 2000'li yılların gezginleri zamanı kullanma ya da zaman hassasiyeti açısından 1970'li yılların gezginlerinden ayrışırken, flashpackerlar da sahip oldukları yüksek bütçe ile 2000'li yılların düşük bütçeli gezginlerinden ayrışmaktadır.

İnsanlar hayatları boyunca istemeseler de bir değişimin içinde yer almaktadır. Doğumundan ölene kadar fiziksel olarak değişime uğradığ gibi, zihinsel anlamda da gelişmekte ve her geçen gün yenilenmektedir. Kişisel gelişim de özü itibariyle insanların yaşadığı olumlu değişimi ifade etmektedir. Daha çok felsefi bir bakış açısıyla ele alınsa da aslında psikoloji, eğitim, yönetim, sosyoloji gibi birçok bilimin önemle üzerinde durduğu bir konudur (Chen, Bao ve Huang, 2014). Santrock'tan aktaran Chen ve Huang (2017) özellikle bilişsel durum, sevgi, zekâ, duygu, ahlak, cinsellik, öz-farkındalık, karakter, dünya görüşü ve dini inanç gibi birçok psikolojik ya da sosyopsikolojik yapı ile yakından ilişkili olduğunu belirtmiştir.

Günümüz dünyasında sayısız turizm türü ve bu türlerin insanlara sağladığı çok çeşitli deneyimler söz konusudur. Yaşanan bu deneyimler, bireylere birçok yönden etki etmekte ve özellikle kişisel ve kolektif kimliğin inşasında önemli bir rol oynamaktadır (Noy, 2004). Aslında ulusal, bölgesel ya da sınıf temelli söylemler ve kolektif kimlik üzerinde yarattı̆̆ etki bir yana daha bireysel ölçekte kişilik duygusuna işaret ederek "Ben nasıl bir insanım?" fikrini inceliyor olması oldukça önemlidir (Desforges, 2000, s.929). Bu sebeple turizm tüketiminin kendilik hissini keşfetmeye çalışan bireyle ilgili olduğu söylenebilir (MacCannell, 1989). Duygu, öz farkındalık ve dünya görüşü ile 
sağlanan kişisel gelişim, turizm faaliyetine katılanların kişiliklerini anlamlandırma ve tamamlamasına katkı sunmaktadır. Bu sayede turistlerin algılanan yaşam kalitesi ve yaşam doyumu arttırılmaktadır. $\mathrm{Bu}$ sebeple günümüzde turistler giderek daha sofistike hale gelmekte ve seyahat deneyimlerinden çeşitli faydalar aramaktadır. Hatta bu varsayımdan hareketle destinasyon pazarlamacılarının ve yöneticilerinin, fiziksel ve zihinsel sağlık, bilişsel öğrenme ve sosyal ilişkiler açısından turistlerin kişisel gelişimlerine katkıda bulunan deneyimler sunması gerektiği de iddia edilmektedir. Ancak turizm faaliyetlerinin kişisel gelişim, özellikle kişisel ve kolektif kimlik yaratma üzerindeki etkisi bu kadar açık olmasına karşın, günümüze değin göz ardı edilen bir konu olmuştur. Bunun yanı sıra genel olarak çağdaş turizmin tipik bir örneği olmamaları sebebiyle sırt çantalı gezginler tarafından sergilenen davranışlar, özellikle kişilerarası iletişim ve etkileşimlerine dair detaylı araştırmalar da oldukça sınırlı kalmıştır (Miao, 2016; Noy, 2004).

Sırt çantalı gezginlerin kişisel gelişimi, seyahatleri sırasında ve sonrasında kendilerinde algıladıkları ya da hissettikleri bir dizi değişiklik olarak ifade edilebilir (Chen, Bao ve Huang, 2014). Ancak kişisel gelişim, seyahat sonucu elde edilen bir çıktı olması (Miao, 2016; Pearce ve Foster, 2007) yanı sıra, uzun yıllar boyunca sırt çantalı gezginleri motive eden bir faktör olarak kabul edilmiştir (Harman, Çakıcı ve Akatay, 2013; O’Reilly, 2006). Buna binaen kişisel gelişimin, sırt çantalı gezginler için bir motivasyon faktörü olduğunu teyit etmeye yönelik hem ulusal hem uluslararası alanda akademik araştırmalar yapılmıştır (Harman, 2014; Harman, Çakıcı ve Akatay, 2013; Noy, 2004; Oliveira-Brochado ve Gameiro, 2013; Paris ve Teye, 2010).

Çıktığı seyahatlerde kişisel gelişim idealine sahip genç gezginlerin çoğu, bu seyahatleri eğitimlerinin keyifli bir parçası olarak görmekte ya da sorumlu yetişkinliğin rollerini üstlenmeden önce bir eğlence ve bağımsızlık dönemi olarak algılamaktadır (O’Reilly, 2006). Eğlenceli olması yanı sıra bu seyahatler sayesinde sırt çantalı gezginlerin küresel bakış açıları ve farkındalıkları artmakta, düşünceleri ve tutumları değişebilmektedir (Thatcher, 2010). Farklı hayat tecrübeleri edindikleri için kendilerini tanımaları (Hsu, 2010'dan aktaran Hsu, Lee ve Chen, 2017) ya da kişiliklerini ve hayattaki rollerini tanımlamaları sağlanmaktadır (O’Reilly, 2006). Bununla birlikte çıktıkları seyahatler kişisel becerileri ve yeteneklerini geliştirmekte (Scarinci ve Pearce, 2012) ve gezginlerin kişiliğinin olumlu anlamda değişmesine sebebiyet vermektedir (Chen, Bao ve Huang, 2014).

Yapılmış araştırmalarda da sırt çantalı gezginlerin kişisel gelişimlerine ya da kişisel gelişimlerine etki eden çeşitli değişkenlere ilişkin birtakım bilgiler elde edilmiştir. Bu çalışmalardan en önemlileri (Akkuş, 2019; Chen ve Huang, 2017; Chen, Bao ve Huang, 2014; Chen, Huang ve Hu, 2018; Hsu, Lee ve Chen, 2017; Miao, 2016; Pearce ve Foster, 2007) ilişkilendirilerek izah edilmiştir.

Bireylerin yetkinliklerinin ya da yeteneklerinin artması demek kişinin bir öğrenme süreci sonrası yaşadığı olumlu deneyimi ifade etmektedir. Pearce ve Foster (2007) da yaptığ1 araştırmada sırt çantalı gezgin seyahatlerinin kişisel gelişimlerine katkı sunan genel becerilerini ya da bireysel yetkinliklerini arttırıp arttırmadığını test etmiş̧tir. Araştırmada sırt çantalı gezginlerin kendilerinin internet üzerinden yayınlanan öğrenme başarıları dikkate alınmıştır. Genel bir beceri öğrenme çerçevesi oluşturularak Kuzey Avustralya'daki 372 sırt çantalı gezgine algılanan genel beceri gelişimi üzerine anketler uygulanmıştır. Gezginler tarafından önemli görülen becerilerin, seyahat deneyimleri sırasında büyük ölçüde gerçekleştirildiği tespit edilmiştir. Bununla birlikte farklı motivasyon kalıplarına sahip gezginlerin farklı beceriler kazandıkları belirlenmiştir.

Chen, Bao ve Huang (2014) sırt çantalı gezginlerin kişisel gelişimlerini ölçmeyi sağlayacak bir ölçek geliştirmiştir. 30 ifadeden oluşan bir anket formu hazırlanmıştır. Bu anketler 397 Çinli sırt çantalı ya da bağımsız seyahat eden öğrenciye uygulanmıştır. Ölçek geliştirme süreci ardından beş boyutlu bir kişisel gelişim modeli ortaya konmuştur. Boyutlar yetenek, duygu, dünya görüşü, beceri ve öz-bilinç olarak adlandırılmıştır. Son olarak, güvenilirlik ve geçerlilik gerekliliklerini karşılayan 16 maddeden oluşan rafine bir ölçek elde edilmiştir. Bu çalışmanın ardından Chen ve Huang (2017) geliştirdikleri ölçeğin kültürlerarası geçerliliğini kanıtlamak amacıyla yeni bir araştırma yapmıştır. Özgün ölçekten farklı olarak bu araştırmada Çin'e gelen Batılı sırt çantalı gezginlere ulaşılmıştır. Araştırma iki aşamada ve iki örneklem üzerinde gerçekleştirilmiştir. İlk aşamada 382 anket, ikinci 
aşamada 120 anket formu değerlendirilmiştir. Sonuçlar ölçekteki beş boyutun Batılı gezginler için de uygun olduğunu kanıtlamıştır. Bir sonraki yıl, Chen, Huang ve Hu (2018) sırt çantalı gezginlerin kişisel gelişiminin öz-yeterlilik ve öz-saygıya etkisi olup olmadığını araştırmak amacıyla yapısal bir model kurmuş ve test etmiştir. Veriler 230 Çinli ve 242 Batılı gezgin olmak üzere farklı kültürel gruplardan toplanmıştır. Çinli gezginlerin beceri gelişiminin öz-yeterliliği pozitif yönde etkilediği, dünya görüşü değişiminin öz-saygıyı negatif yönde etkilediği tespit edilmiştir. Batılı gezginlerin beceri gelişimi ve duygusal uyumlarının öz-yeterliliği pozitif yönde etkilediği belirlenmiştir.

Miao (2016) sırt çantalı gezginlerin kişisel gelişiminde öz-yansımanın rolünü otoetnografik bir perspektiften ele alarak, 2011-2014 yılları arasında gerçekleştirdiği kendi seyahat deneyimlerini değerlendirmiştir. Eşi ile kişisel iletişimi ve günlügü sayesinde seyahat öncesi ve sonrasi günlük yaşamının nasıl değiştiğini irdelemiş ve gezginlerin kişisel gelişimine dair dört önermede bulunmuştur. İlki, seyahat deneyiminin, olumlu ya da olumsuz yoğun duygulara eşlik etmesi nedeniyle öz yansıma için bir tetikleyici olduğudur. İkinci önerme, derin ve uzun vadeli kişisel gelişim, kişinin kendi önyargıları, alışkanlıkları ya da değerlerinin farkındalığına dayanır. Üçüncüsü, örgün eğitim ve ailenin kişisel gelişimi etkileyen diğer önemli faktörler olduğu savından yola çıkarak, gezginin en iyi çıkarımı, rutin hayatta sıkışıp kaldığı an yapabileceği fikrine dayanmaktadır. Son önerme ise, sırt çantalıların kişisel gelişiminin "yolculukla birlikte bilişsel ve sosyo-duygusal olarak olgunlaşma" şeklinde tanımlanabileceğidir.

Hsu, Lee ve Chen (2017) flashpacker'ların seyahat deneyimi, kişisel gelişimi ve seyahat motivasyonu arasındaki ilişkiyi araştırmıştır. Tayvan'ın Taoyuan Uluslararası Havaalanı lobisinde 375 flashpacker'a kolayda örnekleme yöntemi ile ulaşılarak anket formunu doldurmaları sağlanmıştır. Araştırma sonucunda Tayvanlı flashpacker'ların kişisel gelişimi ve seyahat deneyimi ile kişisel gelişimleri ve seyahat motivasyonları arasında ilişki olduğu tespit edilmiştir. Akkuş (2019) ise sırt çantalı gezginlerin kişisel gelişimleri ile sürdürülebilirlik algıları arasındaki ilişkiye odaklanmıştır. Kartopu örneklemesi yöntemiyle yüz yüze ve çevrimiçi ortamda 244 Türk sırt çantalı gezgine ulaşılmıştır. Araştırma sonucunda, tüm kişisel gelişim boyutları ile gezginlerin sürdürülebilirlik algıları arasında anlamlı ilişkiler tespit edilmiştir.

Türkçe yazında sırt çantalı gezginler üzerine yapılmış sınırlı sayıda araştırma bulunmakla birlikte (Akkuş ve Akkuş, 2019; Akkuş, 2019; Harman, 2012; Harman, 2014; Harman, Çakıcı ve Akatay, 2013), genellikle gezginlerin seyahat motivasyonları üzerine odaklanıldığı söylenebilir. Bu araştırmada ise Türk sırt çantalı gezginlerin seyahatleri sonucu hissettikleri kişisel gelişimi tespit edebilmek ve gezginlerin demografik özelliklerine göre kişisel gelişimlerinin farklılaşıp farklılaşmadığını belirlemek amaçlanmıştır.

İster backpacker olsun ister flashpacker, bağımsız seyahat eden tüm gezginlerin ortak amac1, çıktıkları seyahatler ile bir dönüşüm yaşayabilmektir. Seyahatlerin bu kadar uzun tutulması, yerel halkla sürekli temas halinde kalınması, bu durumun en önemli göstergeleridir. Ancak gezginlerin, cinsiyetleri, yaşları ya da yaptıkları iş gibi birtakım demografik özellikleri sebebiyle farklı bir gelişim yaşadığı düşünülmüştür. Bu sebeple araştırmada, Türk sırt çantalı gezginlerin seyahatleri sonucu hissettikleri kişisel gelişimi tespit edebilmek ve gezginlerin demografik özelliklerine göre kişisel gelişimlerinin farklılaşıp farklılaşmadığını belirlemek amaçlanmıştır. Bununla birlikte, yurtdışına çıkan gezginlerin çok daha farklı kültürler tanıyarak dünyaya bakış açılarının değişebileceği varsayımından hareketle, yurt dişına seyahat eden ve etmeyen gezginlerin kişisel gelişimleri arasında herhangi bir farklılık olup olmadığı da araştırılmıştır. Bu araştırma amaçları doğrultusunda geliştirilen dört alt problem şu şekildedir:

1. Türk sırt çantalı gezginlerin kişisel gelişimleri cinsiyetlerine göre farklılık gösteriyor mu?

2. Türk sırt çantalı gezginlerin kişisel gelişimleri yaşlarına göre farklılık gösteriyor mu?

3. Türk sırt çantalı gezginlerin kişisel gelişimleri medeni durumlarına göre farklılık gösteriyor

$\mathrm{mu}$ ?

4. Türk sırt çantalı gezginlerin kişisel gelişimleri yurt dışına seyahat etme durumlarına göre farkl111k gösteriyor mu? 


\section{Yöntem}

Araştırmanın ana amaçları doğrultusunda ortaya konan alt problemleri cevaplamak amacıyla nicel bir araştırma deseni benimsenmiş ve anket tekniğinden faydalanılmıştır. Farklılık testleri aracılığıyla sırt çantalı gezginlerin kişisel gelişimleri ile demografik özellikleri arasındaki ilişki incelenmiştir.

\section{Evren ve Örneklem}

Araştırmanın evrenini Türk sırt çantalı gezginler oluşturmaktadır. Ancak "evrenin büyüklügüne ilişkin herhangi bir istatistikî veri bulunmamaktadır" (Harman, 2014, s.115). Bu sebeple amaçlı örnekleme yöntemlerinden kartopu örneklemesi tercih edilmiş̧ir. İlk örneklem mezun olmuş ya da öğrenim gören öğrenciler içerisinden sırt çantalı gezgin olduğunu ifade eden dört öğrenciden oluşmuştur. Öğrencilerden ikisi Atatürk Üniversitesi Turizm Fakültesi Gastronomi ve Mutfak Sanatları bölümü 4. sınıf öğrencileri, diğer ikisi Kastamonu Üniversitesi Turizm Fakültesi Turizm Rehberliği 4. sınıf, Turizm ve Otel İşletmeciliği 4. sınıf öğrencileridir. Bu öğrencilerin üçü kendi gezgin grupları olduğunu belirtmiş, bir öğrenci ise tanıdığı birkaç gezgin olduğunu ifade etmiştir. Öğrencilerin önerilerinden yola çıkılarak liste genişletilmiş ve tanıdıkları gezginlerin tanıdığ diğer gezginlere de ulaşılmaya çalışılmıştır.

Tablo 1

Katılımcıların Demografik Özelliklerine İlişkin Bulgular

\begin{tabular}{lcclcc}
\hline & $\mathrm{f}$ & $\%$ & & $\mathrm{f}$ & $\%$ \\
\hline Yaş & & & Cinsiyet & & \\
\hline $16-24$ & 102 & 41.8 & Kadın & 110 & 45.1 \\
$25-29$ & 92 & 37.7 & Erkek & 134 & 54.9 \\
$30-34$ & 26 & 10.7 & Medeni Durum & & \\
$35-39$ & 8 & 3.3 & Bekâr & 22 & 91.0 \\
40 ve Üzeri & 16 & 6.6 & Evli Çocuksuz & 10 & 4.1 \\
& & & Evli Çocuklu & 12 & 4.9 \\
Toplam & 244 & 100 & Toplam & 244 & 100 \\
\hline
\end{tabular}

Araştırmaya katılan sırt çantalı gezginlerin demografik özelliklerine ilişkin bilgiler Tablo 1'de sunulmuştur. Gezginlerin \%54,9'u erkek olup, bekârların oranı \%91'dir. Yaş aralıkları değerlendirildiğinde \%41,8 ile büyük yoğunluğun 16-24 aralığında olduğu tespit edilmiştir. Bunu $\% 37,7$ ile 25-29 yaş aralığındaki bireyler takip etmiştir. Eğitim düzeyi en yüksek grubu \%79,9 ile lisans mezunları, en düşük grubu \%1,2 ile ilköğretim mezunları oluşturmaktadır. Demografik değişkenler dışında gezginlere yurt dışına seyahat edip etmedikleri sorulduğunda $\% 57,4$ ile yarısından fazlası yurt dışına seyahat etmediğini, \%42,6'sı seyahat ettiğini belirtmiş̧ir.

\section{Veri Toplama Aracı}

Veri toplama aracı olarak anket tekniği kullanılmıştır. Anketin ilk bölümünde gezginlerin demografik özelliklerini tespit edebilmek amaciyla cinsiyet, yaş, eğitim ve medeni durum bilgileri sorulmuştur. Ardından yurt dışına seyahat etme durumuna ilişkin kapalı uçlu bir soru sorulmuştur.

Sırt çantalı gezginlerin kişisel gelişimlerini ölçebilmek amacıyla Chen, Bao ve Huang (2014) tarafından tasarlanan "Sırt Çantalı Gezgin Kişisel Gelişim Ölçeği”"nden faydalanılmıştır. Bu ölçek tatil ve eğlence literatüründe yer alan ölçeklerden farklı olması ve doğrudan sırt çantalı gezginlerin kişisel gelişimlerine odaklanması sebebiyle tercih edilmiştir. Ölçek yetenek, duygu, beceri, dünya görüşü ve öz bilinç adlı beş boyuttan oluşmaktadır. İlk dört boyutun her birinde üçer ifade, son boyutta dört ifade bulunmaktadır. Anket formunda 7'li Likert ölçeği kullanılmıştır (1= Kesinlikle katılmıyorum, 7= Tamamen katıliyorum). 
Orijinal ölçek İngilizce olup, Türk gezginlere uygulanacağ1 için Türkçeye çevrilmiştir. Bu aşamada ölçek çevirilerinde en sık kullanılan yaklaşımlardan biri olan geleneksel yaklaşım (Hançer, 2003) ile Türkçeye çevrilen ölçeğin güvenilir, geçerli ve aslına uygun olup olmadığı kontrol edilmiştir. Ölçek İngilizce okutmanı bir akademisyen tarafindan öncelikle İngilizceden Türkçeye çevrilmiştir. Ardından çevrilen bu ölçek başka bir İngilizce okutmanı tarafından tekrar orijinal dile çevrilmiştir. Anket formu şekillendikten sonra Turizm İşletmeciliği alanında çalışan üç akademisyenin de görüşü alınarak ifadelere kelime ekleme, çıkarma ve terim ekleme gibi öneriler ile anket daha anlaşılır hale getirilmeye çalışılmştır. Ardından form ilk örnekleme gösterilmiş ve soruların anlaşılırlığını teyit etmeleri istenmiştir. Eklenebilecek ifadeler olup olmadığı sorularak anket formuna son hali verilmiştir.

Çeviriler arasındaki eşitlik her iki dili de akıcı bir şekilde konuşan Kastamonu Üniversitesi Turizm Fakültesi Turizm Rehberliği bölümü 4. sınıf öğrencilerinden oluşan dört kişilik iki farklı grup üzerinde denenmiş ve elde edilen değerlerin birbirleri ile farklılık göstermediği tespit edilmiştir. $(\mathrm{t}=0,129 \mathrm{p}=0,902)$. Bu sayede ölçeğin geçerliliği sağlanmıştır. Ardından on gezgin üzerinde yapılan pilot test neticesinde kişisel gelişim ölçeği 0,983'lük Cronbach's Alpha değeri ile güvenilir bulunmuştur.

Anket formu ilk örnekleme yüz yüze uygulanmış ancak irtibat kurulan diğer gezginlere çevrimiçi olarak ulaştırılması daha uygun bulunmuştur. Web tabanlı anket uygulamanın geleneksel yöntemlere nazaran birçok avantajı bulunmakla birlikte araştırmacılara özellikle mikro hedefli örneklemlere (kütüphane üyeleri, kablo tv. izleyicileri gibi) ulaşma imkânı sağlamaktadır. Diğer anket türlerinde kullanılan teknik ile internet anketlerinin biçimsel çerçevesi aynı olup, beş aşamadan oluşmaktadır. Bu aşamalar anket amaçlarının tanımlanması, örneklem seçimi, ölçme aracı yaratma ve test etme, katılımcılarla temas kurma, veri toplama, değerlendirme ve analizini yapmayı içermektedir (Avcioğlu, 2014).

Online anketler Google Drive aracılığıyla yazarlar tarafindan oluşturulmuş ve ilk örnekleme gönderilmiştir. İlk örneklem ise kendisine ulaşan anket formlarını kendi gezgin gruplarında paylaşmış ya da tanıdığı gezginlere iletmiştir. Bunun yanı sıra anketler bazı ilgili facebook gruplarında paylaşılmıştır. Veriler 2018 yılı Eylül-Ekim aylarında toplanmıştır.

\section{Verilerin Analizi}

Kişisel gelişim ölçeğinin uygunluğunu test etmek amacıyla faktör analizi, gezginlerin kişisel gelişimlerinin demografik özelliklerine göre farklılığını tespit etmek amacıyla t testi, Kruskal Wallis testi ve ANOVA'dan faydalanılmıştır. Veriler SPSS 21.0 Paket İstatistik Programı aracılığıyla analiz edilmiştir.

\section{Bulgular}

Sırt çantalı gezginlerin kişisel gelişimlerini ölçmek amaciyla kullanılan ölçeğe açıklayıcı faktör analizi uygulanmıştır. Verilerin normal dağılım gösterdiği gözlenmiştir. Analizlerde açıklayıcı model olarak temel bileşenler analizi ve varimax döndürme seçenekleri kullanılmıştır. Faktör analizinin sonuçlarına ilişkin değerler Tablo 2'de sunulmuştur.

Tablo 2

Kişisel Gelişim Ölçeği Faktör Analizi Sonuçları

\begin{tabular}{lccccc}
\hline & Ort. & $\begin{array}{c}\text { Faktör } \\
\text { Yükü }\end{array}$ & Öz Değer & $\begin{array}{c}\text { Açılan } \\
\text { Vary. }\end{array}$ & $\begin{array}{c}\text { Cron. } \\
\text { Alp. }\end{array}$ \\
\hline Faktör 1. Farkındalık & & & 3.622 & 24.145 & 0.922 \\
\hline Hayata bakış açım değişti. & 5.83 & 0.799 & & & \\
Değer algım değişti. & 5.72 & 0.759 & & & \\
Dünyaya bakış açım değişti. & 5.84 & 0.756 & & \\
Çevremdeki insanlara bakış açım değişti. & 5.70 & 0.716 & & \\
Bağımsız bir gezgin olma deneyimi farklı & 6.01 & 0.614 & & & \\
\hline
\end{tabular}




\begin{tabular}{|c|c|c|c|c|c|}
\hline \multicolumn{6}{|l|}{ hissetmemi sağladı. } \\
\hline Faktör 2. Yetenek & & & 2.903 & 19.351 & 0.885 \\
\hline İletişim kabiliyetim arttı. & 6.09 & 0.776 & & & \\
\hline Ortama uyum yeteneğim geliști. & 5.76 & 0.758 & & & \\
\hline $\begin{array}{l}\text { Kendi öz disiplinim ve kendimi kontrol etme } \\
\text { durumum yoğunluk kazandi. }\end{array}$ & 5.72 & 0.663 & & & \\
\hline $\begin{array}{l}\text { Sorunları belirleme ve çözme yeteneğim } \\
\text { gelişti. }\end{array}$ & 5.66 & 0.592 & & & \\
\hline Faktör 3. Beceri & & & 2.850 & 19.000 & 0.845 \\
\hline Para yönetimi becerim arttı. & 5.39 & 0.842 & & & \\
\hline $\begin{array}{l}\text { Malzeme (glda, günlük ürünler gibi) } \\
\text { yönetim becerim gelişti. }\end{array}$ & 5.67 & 0.831 & & & \\
\hline Zaman yönetimi becerim artt1. & 5.25 & 0.779 & & & \\
\hline Faktör 4. Duygu & & & 2.221 & 14.808 & 0.790 \\
\hline Olumsuz duygularım iyi bir şekilde düzeldi. & 5.34 & 0.782 & & & \\
\hline Endişe ve stres düzeyim azaldı. & 5.23 & 0.716 & & & \\
\hline Daha önceki hayal kırıklıklarım iyileşti. & 4.72 & 0.649 & & & \\
\hline
\end{tabular}

Açılanan Varyans: 77,304, KMO: 0,906, Bartlett Testi: p <0,000

İlk olarak ölçekte yer alan değişkenlerin Cronbach's Alpha değerlerine ve değişkenler arasındaki ilişki kat sayılarına bakılmıştır. 16 maddeye uygulanan faktör analizi sonucu faktör yükü .40'nin altında kalan bir madde analizden çıkarılmıştır. Genel olarak dört faktörün varyansı toplam açıklama oranı ise \%77,304 olarak gerçekleşmiştir. Faktörlerin varyansı açıklama oranlarına bakıldığında, birbirlerine yakın olmakla birlikte farkındalık faktörünün daha yüksek bir açıklama oranına sahip olduğu görülmektedir.

Faktör analizi sonucu kişisel gelişim ölçeği dört boyut ve 15 maddeden oluşmuştur. Faktörlerdeki maddelerin ifade ettiği anlamlar doğrultusunda Faktör 1: Farkındalık, Faktör 2: Yetenek, Faktör 3: Beceri, Faktör 4: Duygu olarak adlandırılmıştır.

Kişisel gelişim ölçeğinin genel Cronbach's Alpha değeri 0,942'dir. Alt faktörler açısından bakıldığında bu değerler, farkındalık için 0,922 , yetenek için 0,885 , beceri için 0,845 ve duygu için 0,790'dır. Genel olarak kişisel gelişim ölçeği faktörlerinin Cronbach's Alpha değerlerinin sosyal bilime dayalı araştırmalar için güvenilir düzeyde olduğu söylenebilir (Hair, Black, Babin ve Anderson, 2010: 92).

Türk gezginlerin kişisel gelişimleri ile demografik özellikleri arasında anlamlı bir farklılık bulunup bulunmadığını tespit edebilmek amacıyla, elde edilen verilere farklılık analizleri uygulanmıştır. Birinci alt problemi cevaplayabilmek amaçlı cinsiyet demografik değişkeni ile kişisel gelişim boyutlarına yönelik farklılığın incelendiği analiz sonuçları Tablo 3'de verilmiştir. Levene test değerleri incelendiğinde, 0,05 anlamlılık düzeyinin üzerinde olduğu görülmektedir (farkındalık 0,567, yetenek 0,766, beceri 0,298 , duygu 0,771). Bu nedenle parametrik test yöntemi olan bağımsız örneklem $t$ testi uygulanmıştır. Analiz sonucunda gezginlerin kişisel gelişimlerinin cinsiyete göre farklılaşmadığı tespit edilmiştir. Yani kadınlar ile erkeklerin seyahatleri sonucu yaşadıkları kişisel gelişim açısından aralarında anlamlı bir farklılık bulunmamaktadır.

Tablo 3

Kişisel Gelişim ile Cinsiyet Arasındaki Farklılıklara İlişkin t Testi Sonuçları

\begin{tabular}{lllllll}
\hline & Cinsiyet & $\mathrm{N}$ & $\mathrm{X}$ & Std. Sapma & $\mathrm{t}$ & $\mathrm{P}$ \\
\hline Farkındalık & Kadın & 100 & 5.88 & 1.432 & 1.654 & 0.514 \\
& Erkek & 144 & 5.77 & 1.308 & & \\
Yetenek & Kadın & 100 & 5.89 & 1.288 & 0.907 & 0.365 \\
& Erkek & 144 & 5.75 & 1.185 & & \\
Beceri & Kadın & 100 & 5.53 & 1.557 & 0.825 & 0.410 \\
& Erkek & 144 & 5.37 & 1.414 & & \\
Duygu & Kadın & 100 & 5.24 & 1.437 & 1.360 & 0.175 \\
& Erkek & 144 & 4.99 & 1.342 & & \\
\hline
\end{tabular}


Türk gezginlerin kişisel gelişimlerinin yaşlarına göre farklılığının incelendiği analiz sonuçları Tablo 4 ve Tablo 5'de verilmiştir. Levene test değerleri incelendiğinde, duygu boyutunun 0,05 anlamlılık düzeyinin üzerinde olduğu görülmektedir $(0,329)$. Bu nedenle duygu boyutunun yaşa göre farklılı̆ 1 ANOVA testi ile analiz edilmiştir. Farkındalık, yetenek ve beceri boyutları ise 0,05 anlamlılık düzeyinin altındadır (farkındalık 0,000, yetenek 0,000 , beceri 0,004 ). Belirtilen boyutların normal dağılım sergilememesi nedeniyle farklılık incelemesi için non-parametrik test yöntemi olan Kruskal-Wallis testi uygulanmıştır. Analiz sonucunda, duygu boyutunun gezginlerin yaşlarına göre farklılaştı̆̆ tespit edilmiştir.

Tablo 4

Farkındalık, Yetenek ve Beceri Boyutları ile Yaş Grupları Arasındaki Farklllıklara İlişkin KruskalWallis Test Sonuçları

\begin{tabular}{lllllll}
\hline Bağımlı Değişken & Yaş & $\mathrm{N}$ & Sira Ort. & S.D. & $\mathrm{X}^{2}$ & $\mathrm{p}$ \\
\hline \multirow{4}{*}{ Farkındalık } & $16-24$ & 102 & 118.87 & 4 & 8.890 & 0.64 \\
& $25-29$ & 92 & 131.63 & & & \\
& $30-34$ & 26 & 130.81 & & & \\
& $35-39$ & 8 & 61.25 & & & \\
\multirow{5}{*}{ Yetenek } & 40 ve üstü & 16 & 110.25 & & 8.728 & 0.68 \\
& $16-24$ & 102 & 116.58 & 4 & & \\
& $25-29$ & 92 & 132.59 & & & \\
& $30-34$ & 26 & 136.73 & & & \\
\multirow{3}{*}{ Beceri } & $35-39$ & 8 & 74.00 & & & \\
& 40 ve üstü & 16 & 103.38 & & & \\
& $16-24$ & 102 & 124.34 & & & \\
& $25-29$ & 92 & 124.80 & 4 & & \\
& $30-34$ & 26 & 134.04 & & & \\
\hline
\end{tabular}

Tablo 5

Duygu ile Yaş Grupları Arasındaki Farklılıklara İlişskin ANOVA Test Sonuçları

\begin{tabular}{|c|c|c|c|c|c|c|}
\hline $\begin{array}{l}\text { Bağımsız } \\
\text { Değişken }\end{array}$ & $\begin{array}{l}\text { Bağımlı } \\
\text { Değişken }\end{array}$ & $\begin{array}{l}\text { Kareler } \\
\text { Toplamı }\end{array}$ & S.D & Ortalama Kare & $\mathrm{F}$ & Sig. \\
\hline Yaş & Duygu & $\begin{array}{l}18.169 \\
447.377 \\
465.546\end{array}$ & $\begin{array}{l}4 \\
239 \\
243 \\
\end{array}$ & $\begin{array}{l}4.542 \\
1.872\end{array}$ & 2.427 & $0.049^{*}$ \\
\hline
\end{tabular}

Sırt çantalı gezginlerin medeni durumlarına göre yaşadıkları kişisel gelişim farklılığının incelendiği analiz sonuçları Tablo 6'da verilmiştir. Levene test değerleri incelendiğinde, tüm kişisel gelişim boyutlarının 0,05 anlamlılık düzeyinin üzerinde olduğu görülmüştür (farkındalık 0,132, yetenek 0,227, beceri 0,114, duygu 0,193). Bu nedenle kişisel gelişim boyutlarının medeni duruma göre farklılığ 1 ANOVA testi ile analiz edilmiştir. Analiz sonucunda, duygu dışında diğer tüm kişisel gelişim boyutlarının gezginlerin medeni durumlarına göre farklılaştığı tespit edilmiştir.

Tablo 6

Kişisel Gelişim ile Medeni Durum Arasındaki Farklılıklara İlişkin ANOVA Test Sonuçları

\begin{tabular}{lllllll}
\hline $\begin{array}{l}\text { Bağı̆msız } \\
\text { Değişken }\end{array}$ & Bağımlı Değişken & $\begin{array}{l}\text { Kareler } \\
\text { Toplamı }\end{array}$ & S.D & Ortalama Kare & F & Sig. \\
& Farkındalık & 10.795 & 2 & 5.397 & 2.971 & $0.053^{*}$ \\
& & 437.751 & 241 & 1.816 & & \\
\multirow{3}{*}{ Medeni Durum } & Yetenek & 448.546 & 243 & & & \\
& & 10.312 & 2 & 5.156 & 3.488 & $0.032^{*}$ \\
& & 356.201 & 241 & 1.478 & & \\
\hline
\end{tabular}




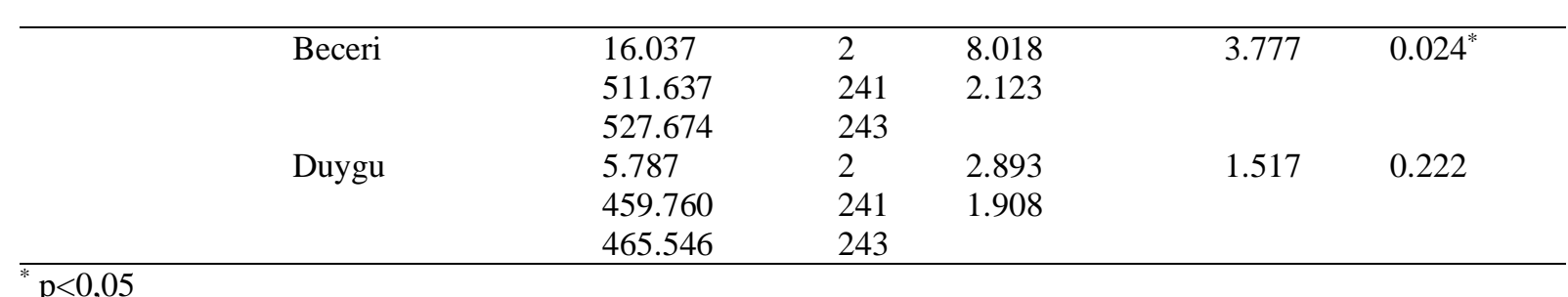

Farkındalık, yetenek ve beceri açısından bekârlar ile evli çocuklular arasında anlamlı farklılıklar tespit edilmiştir. Bekârlar ile evli olup çocuk sahibi olmayan gezginler arasında kişisel gelişim açısından farklılık bulunmazken, bekârlar ile evli olup, çocukları olan gezginler arasında farlılıklar bulunmaktadır. Ayrıca, bekârların daha yüksek ortalamaya sahip olduğu görülmüşstür. Yani bekâr gezginlerin farkındalık, yetenek ve beceri açısından daha yüksek bir kişisel gelişim potansiyeline sahip olduğu söylenebilir.

Yurt dışına seyahat eden ve etmeyen gezginlerin kişisel gelişimleri arasındaki farklılığın incelendiği analiz sonuçları Tablo 7'de verilmiştir. Varyansların homojen olması dolayısıyla bağımsız örneklem $\mathrm{t}$ testi uygulanmıştır.

Tablo 7

Kişisel Gelişim ile Yurt Dışına Seyahat Arasındaki Farklılıklara İlişkin t Testi Sonuçları

\begin{tabular}{lllllll}
\hline & $\begin{array}{l}\text { Yurt Dişına } \\
\text { Seyahat }\end{array}$ & $\mathrm{N}$ & $\mathrm{X}$ & Std. sapma & $\mathrm{t}$ & $\mathrm{p}$ \\
\hline Farkındalık & Evet & 104 & 6.05 & 1.222 & 2.381 & $0.018^{*}$ \\
& Hayır & 140 & 5.64 & 1.430 & & 0.118 \\
Yetenek & Evet & 104 & 5.95 & 1.069 & 1.567 & 0.878 \\
& Hayır & 140 & 5.70 & 1.327 & & 0.317 \\
Beceri & Evet & 104 & 5.42 & 1.496 & -0.153 & \\
& Hayır & 140 & 5.45 & 1.461 & & 1.003 \\
\hline
\end{tabular}

${ }^{*} \mathrm{p}<0,05$

Yurt dışına seyahat eden gezginler ile etmeyenler arasında sadece farkındalık açısından anlamlı farklılık tespit edilmiştir. Yurt dişına seyahat edenlerin daha yüksek bir ortalamaya sahip olması sebebiyle, kişisel gelişim açısından farkındalıklarının daha yüksek olduğu söylenebilir.

\section{Sonuç, Tartışma ve Öneriler}

Yabancı yazında özellikle kırsal ekonomilere sağladığı katk1 sebebiyle sıklıkla araştırma konusu olan sırt çantalı gezginlere yönelik çokça araştırma olmasına rağmen, yerli yazında konuya ilişkin araştırmaların, genellikle gezginlerin seyahat motivasyonları ile sınırlı kaldığı tespit edilmiştir (Harman, 2012; Harman, 2014; Harman, Çakıcı ve Akatay, 2013). Bununla birlikte uluslararası alanda sırt çantalı gezginlerin kişisel değerlerini anlamaya odaklanan çalışmaların da oldukça kısıtlı olduğu ifade edilmektedir (Paris, 2010, s.240). Bu araştırma ile hem yerli hem de yabancı turizm yazınındaki boşluğun doldurulacağı düşünülmektedir.

Araştırmada kartopu örneklemesi yoluyla 244 Türk sirt çantalı gezgine ulaşılmıştır. Gezginlerin daha çok 16-24 yaş aralığındaki lisans mezunu bekâr erkeklerden oluştuğu tespit edilmiştir. Harman'ın (2014) araştırmasında da gezginlerin çoğunun, 30 yaş altı aktif çalışan lisans mezunu bekâr erkeklerden oluştuğu belirlenmiştir. Ancak Harman'ın (2014) araştırmasında Türk gezginlerin çoğu yurt dışına seyahat ettiğini belirtirken, bu araştırmada yurt dışı seyahat edenlerin sayısı daha az bulunmuştur. 
Araştırmada gezginlerin kişisel gelişimleri içinde farkındalık açısından en çok katıldıkları ifade, bu deneyimin farklı hissetmelerini sağlaması olmuştur. Yetenek açısından en çok iletişim kabiliyetlerinin arttığını düşünmektedirler. Beceri ve duygu anlamında biraz daha düşük katılımla malzeme yönetimi becerilerinin arttığını ve olumsuz duygularının iyi bir şekilde düzeldiğini ifade etmişlerdir. Chen, Bao ve Huang'ın (2014) çalışmasında ise benzer şekilde gezginlerin en yüksek katılım sağladığı ilk iki ifade yetenek boyutunda ortaya çıkmıştır. Bununla birlikte en çok katılım sağlanan diğer ifade beceri faktörü içerisinde yer almaktadır.

Araştırmada Türk gezginlerin kişisel gelişimleri ile demografik özellikleri arasında anlamlı bir farklılık bulunup bulunmadığını tespit edebilmek amacıyla, elde edilen verilere farklılık analizleri uygulanmıştır. Cinsiyet ile gezginlerin kişisel gelişimleri arasında anlamlı farklılık bulunmazken, yaş ile kişisel gelişim boyutlarından duygu arasında anlamlı farklılık tespit edilmiştir.

Farkındalık, yetenek ve beceri açısından bekârlar ile evli çocuksuzlar arasında herhangi bir farklılık bulunmazken, evli çocuklular arasında anlamlı farklılıklar tespit edilmiştir. Aslında burada belirgin rolü çocuğun oynadığı söylenebilir. Çünkü çocuğu olanlar ve olmayanlar arasında anlamlı farklılıklar tespit edilmiştir. Bekârlar, çocuklu gezginlere nazaran bakış açısı, iletişim, uyum, sorun çözme yeteneği ve para, malzeme, zaman yönetimi açısından kendilerinin daha fazla gelişim gösterdiğini düşünmektedir. Bunun en önemli sebebi, çocuklu gezginlerin, çocuğa daha fazla odaklanmaları sebebiyle kişisel gelişimlerine dair birtakım ipuçlarını göz ardı etmeleri olabilir. Ancak duygusal açıdan üç grup arasında anlamlı bir farklılık bulunmamaktadır. Yani ister çocuklu olsun ister çocuksuz ya da bekâr, olumsuz duygular, hayal kırıklıkları, endişe gibi duyguların iyileşmesine yönelik benzer algıları paylaşmaktadırlar.

Araştırmaya katılanlar içerisinde, yurt dışına seyahat eden gezginlerin sayısı daha az olmakla birlikte, seyahat eden ve etmeyen gezginlerin yalnızca farkındalık açısından farklılaştı̆̆ tespit edilmiştir. Yurt dışına seyahat eden Türk sırt çantalı gezginler değer algılarının, dünyaya, çevresindeki insanlara, yaşadığı hayata bakış açısının daha fazla değiştiğini düşünmektedir. Bununla birlikte yurt dışına çıkmayan gezginlere göre, gezgin olma deneyiminin farklı hissetmesini sağladığı tespit edilmiştir. Buradan çıkarımla, özellikle yurt dışına seyahat eden gezginlerin dünyaya ve insanlara karşı farkındalıklarının daha fazla arttığı ifade edilebilir.

Araştırma Chen, Bao ve Huang (2014) tarafından tasarlanan sırt çantalı gezgin kişisel gelişim ölçeğinin kültürlerarası geçerliliğine katkı sunma açısından önem arz etmektedir. Bununla birlikte konuya ilişkin araştırmaların devam ettirilmesi ölçeğin geçerliliği ve güvenilirliğini arttıracaktır. Özellikle Türkçe yazında sırt çantalı gezginleri hedef alan kısıtlı sayıda araştırma içerisinde kişisel gelişim gibi gezginleri detaylı bir ş̧ekilde anlamaya çalışan araştırmalar olması literatürü genişletecektir. Sonraki araştırmalarda yurt dışına seyahat eden Türk sırt çantalı gezginlere ulaşılarak kişisel gelişim açısından anıları derinlemesine incelenebilir.

\section{Kaynaklar}

Akkuş, G. (2019). Türk sırt çantalı gezginlerin kişisel gelişimleri ile sürdürülebilirlik algıları arasındaki ilişki, MANAS Sosyal Araştırmalar Dergisi, 8(2), 2125-2144.

Akkuş, G. ve Akkuş, Ç. (2019). Türk sırt çantalı gezginlerin seyahat tarzlarına göre günlük sürdürülebilir uygulamalarının karşılaştırılması, Türk Turizm Araştırmaları Dergisi, 3(3), 306321.

Avcıoğlu, G. Ş. (2014). Sosyal bilimlerde internet anketi uygulamaları: Cevaplama oranı, veri kalitesi, örneklem sorunları ve çözümleri, International Journal of Human Sciences, 11(2), 89-113.

Chen, G., Bao, J. and Huang S. S. (2014). Developing a scale to measure backpackers' personal development, Journal of Travel Research, 53(4), 522-536. 
Chen, G. and Huang, S. S. (2017). Toward a theory of backpacker personal development: crosscultural validation of the bpd scale, Tourism Management, 59, 630-639.

Chen, G., Huang, S. S. and Hu, X. (2018). Backpacker personal development, generalized selfefficacy, and self-esteem: testing a structural model, Journal of Travel Research, 1-15.

Cohen, E. (1973). Nomads from affluence: notes on the phenomenon of drifter-tourism, International Journal of Comparative Sociology, 14(1), 89-103.

Desforges, L. (2000). Traveling the world: 1dentity and travel biography, Annals of Tourism Research, 27(4), 926-945.

Hair, J. F., Black, W. C., Babin, B. J. and Anderson, R. E. (2010). Multivariate data analysis, 7. Bask1, Prentice Hall, New Jersey.

Hançer, M. (2003). Ölçeklerin yazım dilinden başka bir dile çevirileri ve kullanılan değişik yaklaşımlar, Balıkesir Üniversitesi Sosyal Bilimler Enstitüsü Dergisi, 6(10), 47-59.

Harman, S. (2012). Sirtçantal turistlerin seyahat motivasyonları ve ilgilenimleri: İstanbul'a gelen sirtçantalı turistler üzerinde bir araştırma. Doktora Tezi, Çanakkale Onsekiz Mart Üniversitesi, Sosyal Bilimler Enstitüsü, Çanakkale.

Harman, S., Çakıcı, A. C. ve Akatay, A. (2013). İstanbul'a gelen sırtçantalı turistlerin seyahat motivasyonları üzerine bir araştırma, Selçuk Üniversitesi İktisadi ve İdari Bilimler Fakültesi Sosyal ve Ekonomik Araştırmalar Dergisi, 13(25), 267-300.

Harman, S. (2014). Bağımsız seyahat eden yerli gezginlerin seyahat motivasyonları üzerine bir araştırma, Uluslararası Yönetim İktisat ve İşletme Dergisi, 10(21), 107-128.

Hsu, C.-Y., Lee, W.-H. and Chen, W.-Y. (2017). How to catch their attention? taiwanese flashpackers inferring their travel motivation from personal development and travel experience, Asia Pacific Journal of Tourism Research, 22(2), 117-130.

Loker-Murphy, L. ve Pearce, P. (1995). Young budget travelers: backpackers in Australia, Annals of Tourism Research, 22(4), 819-843.

MaccannelL, D. (1989). The tourist: a new theory of the leisure class, Schocken, New York.

Miao, X. (2016). The role of self-reflection in backpackers' personal development: an autoethnographic perspective, Tourism Tribune, 31(11), 22-31.

Noy, C. (2004). This trip really changed me: backpackers' narratives of self-change, Annals of Tourism Research, 31(1), 78-102.

Oliveira-Brochado, A. and Gameiro, C. (2013). Toward a better understanding of backpackers' motivations, TÉKHNE - Review of Applied Management Studies, 11, 92-99.

O'Reilly, C. C. (2006). From drifter to gap year tourist, mainstreaming backpacker travel, Annals of Tourism Research, 33(4), 998-1017.

Paris, C. M. (2010). Backpacker activities and personal values: an SEM approach, Annals of Leisure Research, 13(1-2), 239-258.

Paris, C. M. (2012). Flashpackers: An emerging sub-culture?, Annals of Tourism Research, 39(2), 1094-1115. 
Paris, C. ve Teye, V. (2010). Understanding backpacker motivations: a travel career approach, Journal of Hospitality Marketing \& Management, 19(3), 244-259.

Pearce, P. L. \& Foster, F. A. (2007). 'University of travel': backpacker learning, Tourism Management, 28(5), 1285-1298.

Riley, P. J. (1988). Road culture of international long-term budget travelers, Annals of Tourism Research, 15, 313-328.

Scarinci, J., and Pearce, P. (2012). The perceived influence of travel experiences on learning generic skills, Tourism Management, 33(2), 380-386.

Thatcher, C. A. (2010). International Learning Adventures: A Phenomenological Exploration of International Backpacker-Style Study Abroad. Prescott College (Published Doctoral Dissertation), USA.

Uriely, N., Yonay, Y. and Simchai, D. (2002). Backpacking experiences: a type and form analysis, Annals of Tourism Research, 29(2), 520-538.

Wilson, D. (1997). Paradoxes of tourism in Goa, Annals of Tourism Research, 24(1), 52-75.

Yılmaz, G. (2018). Üniversite gençliğinin turizme bakış açısı: İstanbul Arel Üniversitesi örneği. OPUS -Uluslararası Toplum Araştırmaları Dergisi, 8(15), 1516-1538. 


\section{Extended Abstract}

\section{Introduction}

Independent travelers have been described for the first time by Cohen (1973, p.89) as "drifter. Riley (1988, p.313) stated that these individuals are "international long-term low budget passengers ". However, since the late 1990s, the term "backpacker" (Loker-Murphy and Pearce, 1995, p.819; Wilson, 1997, p.57) has been used. This term has been widely accepted because it shortens Riley's long definition and is catchy (O'Reilly, 2006, p.1000).

The personal development of backpackers can be expressed as a series of changes that they perceive or feel during and after their journey (Chen, Bao \& Huang, 2014, p.525). However, personal development has been accepted as a motivating factor for backpackers for many years as well as being an output obtained from travel (Miao, 2016, p.31; Pearce and Foster, 2007, p.1288) (Harman, Çakıc1) and Akatay, 2013, p.272; O'Reilly, 2006, p. Accordingly, both national and international academic researches have been conducted to confirm that personal development is a motivating factor for backpackers (Harman, 2014; Harman, Çakıcı \& Akatay, 2013; Noy, 2004; Oliveira-Brochado \& Gameiro, 2013; Paris) and Teye, 2010).

Most of the young travelers with the ideal of personal development in their travels see these trips as an enjoyable part of their education or perceive them as a period of entertainment and independence before taking on the roles of responsible adulthood (O'Reilly, 2006, p.998). In addition to being fun, these travels increase the global perspective and awareness of backpackers and change their thoughts and attitudes (Thatcher, 2010, p.211). Because they have different life experiences, they are provided to identify themselves (Hsu, 2010, Hsu, Lee and Chen, 2017, p.120) or to define their personalities and roles in life (O'Reilly, 2006, p.999). However, the journeys they develop develop their personal skills and abilities (Scarinci and Pearce, 2012, p.380) and cause a positive change in the personality of travelers (Chen, Bao and Huang, 2014, p.524). It is aimed to determine the personal development they feel as a result of their travels and to determine whether their personal development differs according to the demographic characteristics of travelers.

\section{Methodology}

Snowball sampling was applied due to the uncertainty of the universe. Survey technique was used as data collection tool. In order to measure the personal development of backpackers, "backpacker personal development scale" designed by Chen, Bao and Huang (2014) was utilized. Data were collected in September-October 2018. Difference analysis were applied to the data

\section{Findings}

Table 1 presents the demographic characteristics of the backpackers. $54.9 \%$ of the travelers are male and the rate of single people is $91 \%$. When the age ranges were evaluated, it was found that the density was in the range of 16-24 with $41.8 \%$. This was followed by individuals between the ages of $25-29$ with $37.7 \%$. The highest level of education consists of undergraduate graduates with $79.9 \%$ and the lowest group consists of primary education graduates with $1.2 \%$. 6 stated that they were traveling.

Explanatory factor analysis was applied to the scale used to measure the personal development of backpackers. As a result of factor analysis, personal development scale was composed of four dimensions and 15 items. Factor 1: Awareness, Factor 2: Ability, Factor 3: Skill, Factor 4: Emotion were named according to the meaning of the items in the factors.

In order to answering the first problem, the gender demographic variable and the differences between the dimensions of personal development were analyzed. In other words, there is no significant difference between women and men in terms of their personal development as a result of their travels. 
Since it was found out that the emotions differ from the personal development dimensions according to the age of the travelers, the second problem which was established as kişisel the personal development of the Turkish backpackers varies according to their age "was accepted.

As a result of the analysis, the difference of personal development experienced by backpackers according to their marital status was found to be different from all other personal development dimensions according to the marital status of travelers. Significant differences were found between singles and married children in terms of awareness, ability and skill. While there is no difference in terms of personal development between single and single travelers who do not have children, there are differences between single and single travelers who have children. In addition, singles have a higher average. For this reason, the third problem was established as kişisel the personal development of Turkish backpackers varies according to their marital status.

A significant difference was found only between the travelers traveling abroad and those who did not. It can be said that those who travel abroad have a higher average, so they are more aware of their personal development. For this reason, the fourth problem, which was established as kişisel the personal development of Turkish backpackers, varies according to their travel abroad hip.

\section{Results}

Among the participants, although the number of travelers traveling abroad was less, it was found that traveling and non-traveling travelers differed only in awareness. Turkish backpackers who travel abroad think that their perceptions of value, their view of the world, the people around them and the life they live in have changed more. However, it has been found that the experience of being a traveler makes you feel different than the travelers who do not go abroad. In conclusion, it can be stated that the awareness of the travelers traveling abroad especially towards the world and people has increased more.

The research is important for contributing to the cross-cultural validity of the backpack traveler personal development scale designed by Chen, Bao and Huang (2014). However, the continuation of the researches on the subject will increase the validity and reliability of the scale. In a limited number of studies aimed at backpackers, especially in the Turkish summer, there will be extensive research on personal development such as personal development. In subsequent studies, Turkish backpackers traveling abroad can be reached and examined in depth in terms of personal development. 